\title{
Effect of Pingchuan Guben decoction on patients with chronic obstructive pulmonary disease: Results from a randomized comparative effectiveness research trial
}

\author{
CHENG-LIANG QIAN and RONG FAN \\ Department of Chinese Medicine, Nanjing BenQ Center, The Affiliated BenQ Hospital \\ of Nanjing Medical University, Nanjing, Jiangsu 210000, P.R. China
}

Received August 10, 2016; Accepted May 11, 2017

DOI: $10.3892 /$ etm.2017.5018

\begin{abstract}
Chronic obstructive pulmonary disease (COPD) is known to be a systemic low-grade ongoing inflammation exerting major health and economic burden worldwide. Complementary and alternative medicines, such as Traditional Chinese Medicine, are widely used for the treatment of patients with COPD. The present study was designed to investigate the efficacy of Pingchuan Guben decoction on patients with COPD through a double-blinded, open-labeled, randomized controlled trial. A total of 86 patients were randomly assigned to two groups, with 43 patients in the intervention group and 43 cases in the control group. The patients in the control group were treated with conventional western medicine, and the intervention group received a combination of conventional western medicine and Pingchuan Guben decoction. After 12 weeks of treatment, the mean 6-minute walking distance, forced expiratory volume in $1 \mathrm{sec}$ (FEV1), forced vital capacity (FVC) and FEV1/FVC in the intervention group were significantly higher than those of the control group $(\mathrm{P}<0.05)$. The levels of inflammation factors and protease molecules were significantly ameliorated in the intervention group compared with the control group $(\mathrm{P}<0.05)$. The levels of Kelch-like ECH-associated protein 1 (Keap1), nuclear factor-E2-related factor-2 (Nrf2), superoxide anions, malondialdehyde, glutathione S-transferase and glutathione peroxidase were significantly more improved in the intervention group compared with those in the control group over the 12 -week study period $(\mathrm{P}<0.05)$. Therefore, combinations of western medicine with Pingchuan Guben decoction may exert
\end{abstract}

Correspondence to: Dr Rong Fan, Department of Chinese Medicine, Nanjing BenQ Center, The Affiliated BenQ Hospital of Nanjing Medical University, 71 Hexi Street, Nanjing, Jiangsu 210000, P.R. China

E-mail: rongfannjmj@yeah.net

Key words: chronic obstructive pulmonary disease, Traditional Chinese Medicine, inflammation factors, Kelch-like ECH-associated protein 1, nuclear factor-E2-related factor-2 therapeutic effects on patients with COPD via modulations of inflammation factors and protease molecules, as well as the activation of the Keap1/Nrf2 signaling pathway.

\section{Introduction}

Chronic obstructive pulmonary disease (COPD) is one of the most life-threatening diseases with high morbidity and mortality rates $(1,2)$. It is estimated that 65 million people may suffer from moderate or severe COPD (3). The prevalence of COPD ranges from 5.4-13.4\% in Asian countries (4). Disabilities as a result of COPD are predicted to be continuously increasing around the world (4). Smoking cessation and supplemental oxygen are used to slow disease progression and decrease the mortality of COPD (5). In addition, western medicines are also frequently applied in clinical treatment of COPD (6). However, effects of these therapeutic measures are disappointing, and efforts to treat COPD need to be improved. Therefore, it is critical to identify novel strategies to prevent the development and progression of COPD. The improvement of lung function and quality of life, and reductions in symptoms and exacerbations will be the predominant focus in future management of COPD (7).

Although the possible pathogenetic mechanisms of COPD have been widely explored, the holistic understanding of COPD remains largely unknown. It is evidenced that COPD is generally associated with inflammatory processes and oxidative stress $(8,9)$. Inflammation-induced inflammatory mediators are involved in lesions of the airways, lung parenchyma and pulmonary vessels of patients with COPD (10). Oxidative stress is one of the key components in the airflow limitation of patients with COPD $(11,12)$. Oxidative stress is a major contributor to various pathogenic processes in the lungs (13). Cigarette smoke and inflammatory cell-derived reactive oxygen species are critical for the increased oxidative stress in patients with COPD (12). Depression of inflammation or oxidative stress may be important approaches for the treatment of COPD (14).

Traditional Chinese Medicine (TCM) has been used as a therapeutic alternative for COPD and has been used in the treatment of various other diseases for many years (15). TCM has recently been demonstrated to have therapeutic effects 
for patients with COPD associated with improvement in lung function, clinical symptoms and quality of life (16). The present study was designed to investigate the effects of Pingchuan Guben decoction on clinical symptoms, lung function, quality of life, inflammation and oxidative stress in patients with COPD.

\section{Patients and methods}

Patients. The present clinical study was approved by the Ethics Committee of Nanjing BenQ Hospital (Nanjing, China) and was conducted following the ethical standards for human experimentation (17). Subjects provided written informed consent prior to initiation of the study. A total of 86 patients were enrolled from January 2013 and October 2015, 62 males $(72.1 \%)$ and 24 females $(27.9 \%)$. All experiments were performed in accordance with relevant guidelines and regulations. The authors were registered to perform all related trials. The present clinical research was a Phase II clinical trial (ChiCTR-TRC-15001143).

Inclusion and exclusion criteria. Patients were enrolled in the present study under the following inclusion criteria: i) Patients met the diagnostic criteria of global strategies for the diagnosis, management, and prevention of COPD reported by Global Initiative for Chronic Obstructive Lung Disease (GOLD) (18); ii) patients met TCM pattern criteria of stable or acute exacerbation COPD (19); iii) patients were aged between 40-75 years; iv) patients voluntarily participated in the study; v) patients completed and submitted the informed consent form; and vi) patients received no treatment for at least 2 weeks prior to participation in the study (1). Patients were excluded from the present study for the following reasons: i) Patients had airflow limitation due to lung cancer, cystic fibrosis or other respiratory diseases; ii) patients suffered from acute heart failure, aplastic anemia, acute cerebral hemorrhage, coronary heart disease, diabetes, hypertension or other life-threatening diseases; iii) patients used immunosuppressive agent therapy within 2 weeks of study initiation; iv) female patients who were pregnant or breastfeeding; v) patients were allergic to western drugs or Chinese herbs used in the trial; and vi) patients received other medicinal interventions to treat COPD in the last 3 months prior to initiation of the study (20).

Randomization and clinical treatment. The enrolled subjects were randomly allocated into two groups using ClinStat software (version 8.3.2; ClinStat, Chicago, IL, USA). Of the 86 enrolled patients, 43 patients were allocated to the control group and treated with western medicine. The patients were treated according to the Chinese Treatment Guidelines of COPD, as previously reported (10). For patients in the control group with mild COPD, 200 inhalations of albuterol sulfate (inhalation aerosol; $100 \mu \mathrm{g} /$ dose; Ventolin; GlaxoSmithKline, Brentford, UK) were used per day. For patients with moderate COPD, 60 inhalations of fumarate dehydrate (inhalation powder; $4.5 \mu \mathrm{g} /$ dose; Oxis Turbohaler; AstraZeneca, Cambridge, UK) were used per day. For patients with severe COPD, 60 inhalations of salmeterol/fluticasone propionate (dry powder inhaler; $50 \mu \mathrm{g} / \mathrm{dose}$; Seretide; GlaxoSmithKline) were used per day.
The remaining 43 cases were allocated to the intervention group and received western medicine plus TCM Pingchuan Guben decoction therapeutics. Pingchuan Guben decoction was composed of $15 \mathrm{~g}$ Salvia miltiorrhiza, $15 \mathrm{~g}$ suzi, $6 \mathrm{~g}$ Schisandra chinensis, $6 \mathrm{~g}$ agilawood, $6 \mathrm{~g}$ exocarpium citri, $12 \mathrm{~g}$ walnut, $12 \mathrm{~g}$ coltsfoot flower, $12 \mathrm{~g}$ Pinellia, $18 \mathrm{~g}$ magnetitum, $3 \mathrm{~g}$ Cordyceps sinensis and $3 \mathrm{~g}$ dried human placenta (Guizhou Sanli Pharmaceutical Co., Ltd., Guiyang, China). The mixture was dissolved in $500 \mathrm{ml}$ water and evaporated to $150 \mathrm{ml}$. The patients were recommended to have $75 \mathrm{ml}$ Pingchuan Guben decoction orally twice daily.

Primary endpoint. The primary endpoints for the present study were the clinical symptoms and the quality of life. The clinical efficacy was evaluated as previously reported (21). When clinical symptoms of COPD disappeared and total TCM syndrome scores reduced by $95-100 \%$, the treatment was considered as clinical control and defined as I. When clinical symptoms of COPD disappeared and total TCM syndrome scores reduced by $75-96 \%$, the treatment was recognized as significantly effective and set as II. If some clinical symptoms of COPD improved and total TCM syndrome scores reduced by $30-75 \%$, the treatment was described as effective and defined as III. If clinical symptoms did not improve or even deteriorate, and total TCM syndrome scores decreased by $<30 \%$, the treatment was regarded as ineffective and defined as IV. The acute exacerbation of COPD was diagnosed based on the diagnostic criteria by GOLD and the Chinese Society of Respiratory Diseases (2007 version) (21). The frequency and duration of acute exacerbation during the period of treatment were recorded for 12 weeks as previously described (19). The general and mental health subscales in the Medical Outcomes 36-Item Short Form Health Survey (SF-36) and St. George's Respiratory Questionnaire (SGRQ) were adopted to estimate the quality of life in the two groups, as previously described (22).

Pulmonary function and 6-min walking distance (6MWD). The 6MWD was applied to assess the distance a person was able to walk on a flat surface within $6 \mathrm{~min}$, which was measured before and after treatment. For evaluation of pulmonary function, forced vital capacity (FVC), forced expiratory volume in $1 \mathrm{sec}$ (FEV1), FEV1/predicted value, FEV1/FVC, mean maximum expiratory flow (MMEF) 75/25 and peak expiratory flow (PEF) were also tested (21).

TCM syndrome score evaluation. The assessment of TCM syndrome was carried out as previously described (23), which was measured before and after treatment. The total score represented the severity of symptoms predominantly including cough, expectoration and shortness of breath. The severity of each symptom was divided into four degrees: A score of 0 indicated no symptom of COPD; a score of 2 represented mild symptoms of COPD; a score of 4 suggested moderate symptoms of COPD; and a score of 6 implied severe symptoms of COPD. The higher the total scores, the more serious the symptoms (21).

Collection of sputum and serum samples. Sputum induction was obtained prior to and after 12 weeks of therapy. From all participants, $5 \mathrm{ml}$ venous blood prior to and after treatment was drawn into serum tubes, clotted at room temperature 


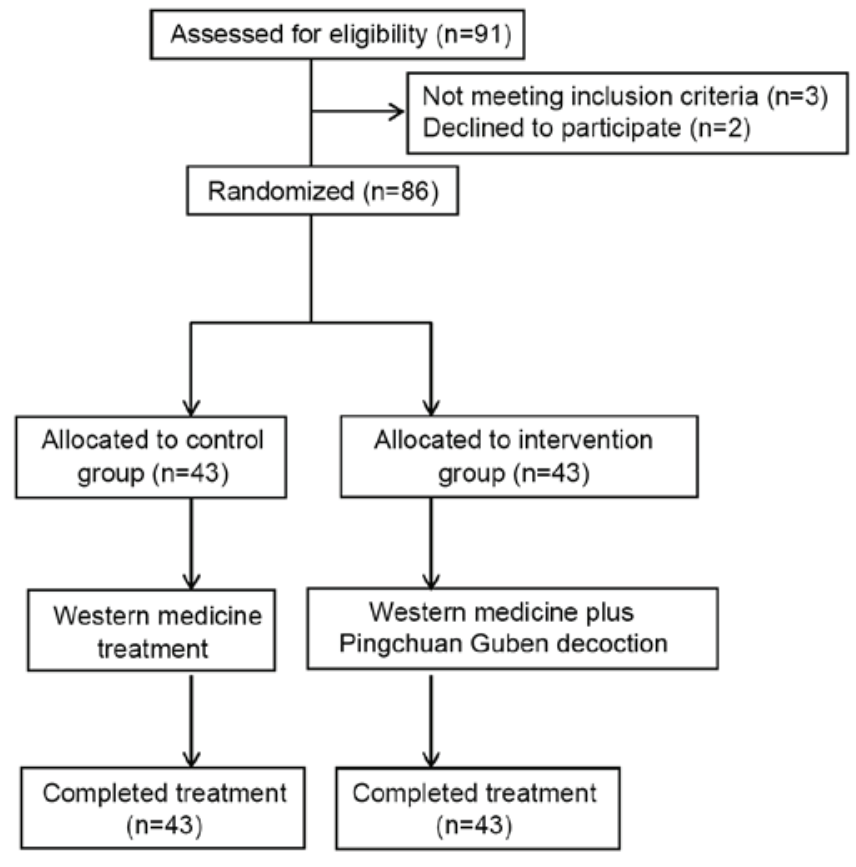

Figure 1. Consort flow diagram of participant enrollment.

for 30-60 min, and then centrifuged at 1,500 $\mathrm{x}$ g for $15 \mathrm{~min}$ at $4^{\circ} \mathrm{C}$. Serum samples were stored and frozen at $-80^{\circ} \mathrm{C}$ prior to analysis (23).

Detection of inflammation-related factors. Serum surfactant protein D (SP-D; cat. no. DSFPD0; R\&D Systems, Inc., Minneapolis, MN, USA), procalcitonin (PCT; cat. no. O00214; RayBiotech Inc.,Norcross, GA, USA), soluble triggering receptor expressed on myeloid cell-1 (sTREM-1; cat. no. MBS9310020; MyBioSource, Inc., San Diego, CA, USA), interferon-G induced protein 10 (IP-10; cat. no. HM2031. HyCult Biotech, Uden, The Netherlands) and tumor necrosis factor-related apoptosis-inducing ligand (TRAIL; cat. no. ABIN579401; Sciencell Research Laboratories, Carlsbad, CA, USA) levels were analyzed with commercial ELISA kits, following the manufacturer's protocols. Serum amylase A (SAA) was determined by an automatic chemistry analyzer (Vitros 3600; Johnson \& Johnson, New Brunswick, NJ, USA).

Measurement of inflammation protease molecules. The concentration of serum neutrophil elastase (NE) was determined with a commercial ELISA kit (cat. no. BMS269; Thermo Fisher Scientific, Inc., Waltham, MA, USA), following the manufacturer's instructions. ELISA was employed to detect secretory leukocyte protease inhibitor (SLPI; cat. no. DPI00) and tissue inhibitor of metalloproteinase 1 (TIMP-1; cat. no. DTM100) in both groups at the same period (R\&D Systems, Inc.). Serum concentrations of serum $\alpha 1$-antitrypsin ( $\alpha 1$-AT) were measured using nephelometry (OUVV15; Dade Behring Marburg GmbH, Frankfurt, Germany), according to the manufacturer's suggestions.

Reverse transcription-quantitative polymerase chain reaction ( $R T-q P C R)$. mRNA expression levels of Kelch-like $\mathrm{ECH}$-associated protein (Keap1) and nuclear factor-E2-related factor-2 (Nrf2) in induced sputum were quantified with a fluorescence quantitative PCR system (Roche Diagnostics, Basel, Switzerland). Briefly, total RNA was obtained using TRIzol reagent (Ambion; Thermo Fisher Scientific, Inc.) and cDNA was synthesized with a cDNA synthesis kit. (R222-01; Vazyme Biotech Co., Ltd., Nanjing, China) according to the manufacturer's instructions. The expression levels of target mRNA were determined by qPCR using a SYBR pre-mixed system (Q321-01; Vazyme Biotech Co., Ltd.) according to the manufacturer's instructions and specific primers. After being denatured at $94^{\circ} \mathrm{C}$ for $5 \mathrm{~min}$, the solution underwent PCR for targeted genes at $94^{\circ} \mathrm{C}$ for $20 \mathrm{sec}, 62^{\circ} \mathrm{C}$ for $30 \mathrm{sec}$ and $72^{\circ} \mathrm{C}$ for $45 \mathrm{sec}$ for 45 cycles. All experiments were conducted in triplicate in each sample, and the average cycle thresholds were used to determine fold-change using the $2^{-\Delta \Delta \mathrm{Cq}}$ method (24). The relative quantification of gene expression was reported as a relative quantity to the $\beta$-actin internal control value. The primer sequences used were as follows: Keap1, forward 5'-GGG TCCCCTACAGCCAAG-3' and reverse 5'-TGGGGTTCCAGA AGATAAGC-3'; Nrf2, forward 5'-ACACGGTCCACAGCT CATC-3' and reverse 5'-TGCCTCCAAAGTATGTCAATC A-3'; and $\beta$-actin, forward 5'-CCAACCGCGAGAAGATGA-3' and reverse 5'-CCAGAGGCGTACAGGGATAG-3'.

Measurement of malondialdehyde (MDA), glutathione $S$-transferases (GST) and glutathione peroxidase (GPX) levels. The MDA (A003-1, TBA method), GST (A061-1, Colorimetry) and GPX levels (A061-1, Colorimetry) in induced sputum were examined using commercial assay kits (Nanjing Jiancheng Bioengineering Institute, Nanjing, China), according to the manufacturer's protocols. The reactions were stopped with stop solution and read at $532 \mathrm{~nm}$ using a microtiter plate reader (ELX800; BioTek Instruments, Inc., Winooski, VT, USA). The MDA, GST and GPX levels were normalized to protein contents in induced sputum of each sample.

Measurement of superoxide anions. The level of superoxide anions in induced sputum was determined using a lucigenin-derived chemiluminescence method, as previously reported (25). In brief, the superoxide anion level was measured based on the photon emission induced by dark-adapted lucigenin. (Sigma-Aldrich; Merck KGaA, Darmstadt, Germany). Light emission was detected 10 times in 10 min with the aid of a luminometer (20/20n; Turner BioSystems, Sunnyvale, CA, USA). The value of superoxide anion was described by mean light unit/min/mg protein.

Statistical analysis. All statistical analyses were performed using SPSS v. 19.0 (IBM Corp., Armonk, NY, USA). Quantitative data were presented as the mean \pm standard deviation. Numerical data were expressed as constituent ratios. A single sample Kolmogorov-Smirnov non-parametric test was used to determine the uniformly of parameters. Student's t-tests and Fisher's exact tests were employed to compare the baseline characteristics between two groups. Paired t-tests were used for before and after treatment comparisons within the intervention and control groups, while independent samples t-tests or Mann-Whitney U tests were used based on data distribution to compare differences between two groups. The $\chi^{2}$ test or Fisher's exact test was used to compare the proportion of categorical variables between 
Table I. Baseline characteristics of the patients in the control and intervention groups.

\begin{tabular}{|c|c|c|c|c|}
\hline \multirow[b]{2}{*}{ Characteristics } & \multicolumn{2}{|c|}{ Group } & \multirow[b]{2}{*}{$\chi^{2}$, t-test } & \multirow[b]{2}{*}{ P-value } \\
\hline & Control & Intervention & & \\
\hline Age, years & $64.7 \pm 11.5$ & $63.8 \pm 12.9$ & 1.517 & 0.164 \\
\hline \multicolumn{5}{|l|}{ Sex, n (\%) } \\
\hline Male & $32(74.4)$ & $30(69.8)$ & 0.231 & 0.631 \\
\hline Female & $11(25.6)$ & $13(30.2)$ & & \\
\hline \multicolumn{5}{|l|}{ Ethnicity, n (\%) } \\
\hline Han & $41(95.3)$ & $42(97.7)$ & 0.345 & 0.557 \\
\hline Minority & $2(4.7)$ & $1(2.3)$ & & \\
\hline $\mathrm{BMI}, \mathrm{kg} / \mathrm{m}^{2}$ & $22.4 \pm 2.6$ & $23.1 \pm 2.7$ & 1.536 & 0.159 \\
\hline \multicolumn{5}{|l|}{ Smoking status, n (\%) } \\
\hline Currently smoking & $32(74.4)$ & $34(79.1)$ & 0.261 & 0.610 \\
\hline Non-smoking & $11(25.6)$ & $9(20.9)$ & & \\
\hline \multicolumn{5}{|c|}{ GOLD classification, $\mathrm{n}(\%)$} \\
\hline I & $7(16.3)$ & $6(14.0)$ & 0.091 & 0.763 \\
\hline II & $16(37.2)$ & $15(34.9)$ & 0.050 & 0.822 \\
\hline III & $20(46.5)$ & $22(51.1)$ & 0.186 & 0.666 \\
\hline Systolic BP, mmHg & $136.1 \pm 18.5$ & $132.3 \pm 21.4$ & 2.142 & 0.061 \\
\hline Diastolic BP, mmHg & $78.2 \pm 10.3$ & $77.4 \pm 12.1$ & 0.863 & 0.411 \\
\hline
\end{tabular}

Data are presented as the mean \pm standard deviation where appropriate. BMI, body mass index; BP, blood pressure; GOLD, Global Initiative for Chronic Obstructive Lung Disease.

Table II. Comparison of clinical efficacy between the control and intervention treatments.

\begin{tabular}{lccccccrr}
\hline & & \multicolumn{5}{c}{ Clinical efficacy score, $\mathrm{n}$} & & \\
\cline { 3 - 6 } Group & $\mathrm{n}$ & I & II & III & IV & Total effective rate, $\mathrm{n}(\%)$ & $\chi^{2}$ & P-value \\
\hline Control & 43 & 0 & 2 & 9 & 32 & $11(25.6)$ & 9.364 & 0.002 \\
Intervention & 43 & 0 & 6 & 19 & 18 & $25(58.1)$ & & \\
\hline
\end{tabular}

I, clinical control; II, significantly effective; III, effective; IV, ineffective.

two groups. $\mathrm{P}<0.05$ was considered to indicate a statistically significant difference.

\section{Results}

Baseline data of the patients between two groups. A total of 91 patients with COPD were approached, of whom 86 conformed to the inclusion criteria. A total of 86 subjects with COPD were enrolled and agreed to participate and continue with this research (Fig. 1). The patients were randomly allocated into each group ( $n=43$ per group). There were no significant differences in baseline clinical data and demographics between the two groups (Table I).

Comparison of the clinical efficacy, and frequency and duration of acute exacerbation. Of 43 patients in the control group, the clinical efficacy rate was $25.6 \%$, which was significantly lower than the value of $58.1 \%$ in the intervention group $(\mathrm{P}=0.002$; Table II). At the end of the 12 weeks, the average frequency $(\mathrm{P}=0.006)$ and duration $(\mathrm{P}=0.013)$ of acute exacerbation were significantly decreased in the intervention group compared with the control group (Table III). In addition, the intervention group had a significantly lower number of patients that demonstrated acute exacerbation $(\mathrm{P}<0.001$; Table III $)$.

Comparison of changes in pulmonary function from baseline to 12-weeks follow-up. Prior to treatment, there was no significant difference in the mean value of 6MWD, FEV1, FVC, FEV1/FVC, MMEF75/25 and PEF between the two groups. At week 12, the mean values of $6 \mathrm{MWD}(\mathrm{P}=0.027)$, FEV1 $(\mathrm{P}<0.001), \mathrm{FVC}(\mathrm{P}<0.001)$ and FEV1/FVC $(\mathrm{P}=0.005)$ in the 
Table III. Comparison of the frequency and duration of acute exacerbation in the control and intervention groups.

\begin{tabular}{|c|c|c|c|c|}
\hline \multirow[b]{2}{*}{ Variable } & \multicolumn{2}{|c|}{ Group } & \multirow[b]{2}{*}{$\chi^{2}$, t-test } & \multirow[b]{2}{*}{ P-value } \\
\hline & Control & Intervention & & \\
\hline Frequency of acute exacerbation & $1.96 \pm 1.42$ & $1.01 \pm 1.14$ & 3.601 & 0.006 \\
\hline \multicolumn{5}{|l|}{ Exacerbation, n } \\
\hline Yes & 31 & 10 & 20.556 & $<0.001$ \\
\hline No & 12 & 33 & 20.556 & $<0.001$ \\
\hline Duration, days & $6.3 \pm 3.4$ & $4.1 \pm 1.9$ & 3.009 & 0.013 \\
\hline
\end{tabular}

Data are presented as the mean \pm standard deviation where appropriate.

Table IV. Comparison of changes in pulmonary function between baseline and after 12 weeks of treatment.

\begin{tabular}{|c|c|c|c|}
\hline \multirow[b]{2}{*}{ Outcome measurement } & \multicolumn{2}{|c|}{ Experimental time } & \multirow{2}{*}{$\begin{array}{c}\text { Intervention by time } \\
\text { interaction } \\
\text { (t-test/P-value })\end{array}$} \\
\hline & Baseline & 12-week follow-up & \\
\hline \multicolumn{4}{|l|}{$6 \mathrm{MWD}, \mathrm{m}$} \\
\hline Control & $298.5 \pm 22.8$ & $317.6 \pm 23.7$ & $3.058 / 0.014$ \\
\hline Intervention & $296.4 \pm 19.8$ & $345.6 \pm 25.2$ & $6.152 /<0.001$ \\
\hline Intervention vs. Control (t/P-value) & $0.126 / 0.834$ & $2.633 / 0.027$ & \\
\hline \multicolumn{4}{|l|}{ FEV 1,1} \\
\hline Control & $1.3 \pm 0.7$ & $1.3 \pm 0.8$ & $1.104 / 0.337$ \\
\hline Intervention & $1.3 \pm 0.5$ & $1.6 \pm 0.6$ & $4.649 / 0.001$ \\
\hline Intervention vs. Control (t/P-value) & $0.684 / 0.511$ & $5.833 /<0.001$ & \\
\hline \multicolumn{4}{|l|}{ FVC, 1} \\
\hline Control & $2.2 \pm 0.9$ & $2.2 \pm 1.1$ & $1.120 / 0.292$ \\
\hline Intervention & $2.1 \pm 0.8$ & $2.6 \pm 1.2$ & $2.816 / 0.020$ \\
\hline Intervention vs. Control (t/P-value) & $1.055 / 0.319$ & $5.452 /<0.001$ & \\
\hline \multicolumn{4}{|l|}{ FEV1, \% } \\
\hline Control & $44.7 \pm 16.9$ & $46.6 \pm 18.5$ & $1.655 / 0.132$ \\
\hline Intervention & $45.1 \pm 17.4$ & $55.3 \pm 21.2$ & $4.486 / 0.002$ \\
\hline Intervention vs. Control (t/P-value) & $2.011 / 0.075$ & $7.629 /<0.001$ & \\
\hline \multicolumn{4}{|l|}{ FEV1/FVC, \% } \\
\hline Control & $54.4 \pm 17.2$ & $56.2 \pm 18.9$ & $1.390 / 0.198$ \\
\hline Intervention & $53.2 \pm 15.5$ & $67.4 \pm 16.4$ & $3.893 / 0.004$ \\
\hline Intervention vs. Control (t/P-value) & $1.039 / 0.326$ & $3.722 / 0.005$ & \\
\hline \multicolumn{4}{|l|}{ MMEF $75 / 25, \%$} \\
\hline Control & $19.4 \pm 11.8$ & $20.1 \pm 13.1$ & $1.234 / 0.249$ \\
\hline Intervention & $19.6 \pm 11.9$ & $21.4 \pm 14.2$ & $0.077 / 0.941$ \\
\hline Intervention vs. Control (t/P-value) & $0.288 / 0.780$ & $0.910 / 0.387$ & \\
\hline \multicolumn{4}{|l|}{$\mathrm{PEF}, 1 / \mathrm{min}$} \\
\hline Control & $41.6 \pm 14.3$ & $43.6 \pm 14.9$ & $0.254 / 0.805$ \\
\hline Intervention & $42.1 \pm 13.4$ & $44.8 \pm 15.4$ & $0.627 / 0.546$ \\
\hline Intervention vs. Control (t/P-value) & $0.085 / 0.934$ & $0.394 / 0.702$ & \\
\hline
\end{tabular}

Data are presented as the mean \pm standard deviation. $6 \mathrm{MWD}, 6$-min walking distance; FEV1, forced expiratory volume in 1 sec; FVC, forced vital capacity; MMEF, mean maximum expiratory flow; PEF, peak expiratory flow.

intervention group were significantly higher than those of the control group (Table IV). However, there were no significant differences in MMEF75/25 or PEF between the two groups before or after treatment $(\mathrm{P}>0.05$; Table IV). 
Table V. Comparison of the total TCM syndrome score, SF-36 scores and SGRQ scores.

\begin{tabular}{|c|c|c|c|}
\hline \multirow[b]{2}{*}{ Outcome measurement } & \multicolumn{2}{|c|}{ Experimental time } & \multirow{2}{*}{$\begin{array}{c}\text { Intervention by time } \\
\text { interaction } \\
\text { (t-test/P-value) }\end{array}$} \\
\hline & Baseline & 12-week follow-up & \\
\hline \multicolumn{4}{|l|}{ Total score of TCM syndrome } \\
\hline Control & $13.4 \pm 5.8$ & $9.8 \pm 3.4$ & $2.310 / 0.046$ \\
\hline Intervention & $13.5 \pm 6.1$ & $5.2 \pm 2.1$ & $3.490 / 0.007$ \\
\hline Intervention vs. Control (t/P-value) & $2.121 / 0.063$ & $3.812 / 0.004$ & \\
\hline \multicolumn{4}{|l|}{ SGRQ scores (respiratory symptoms) } \\
\hline Control & $51.2 \pm 18.2$ & $40.2 \pm 14.5$ & $3.091 / 0.013$ \\
\hline Intervention & $52.8 \pm 17.2$ & $31.1 \pm 11.2$ & $6.137 /<0.001$ \\
\hline Intervention vs. Control (t/P-value) & $0.284 / 0.783$ & $7.155 /<0.001$ & \\
\hline \multicolumn{4}{|l|}{ SGRQ scores (activity limitation) } \\
\hline Control & $55.2 \pm 16.8$ & $47.2 \pm 11.6$ & $3.218 / 0.011$ \\
\hline Intervention & $56.2 \pm 15.6$ & $34.6 \pm 8.5$ & $7.737 /<0.001$ \\
\hline Intervention vs. Control (t/P-value) & $0.780 / 0.456$ & $4.718 /<0.001$ & \\
\hline \multicolumn{4}{|l|}{ SGRQ score (disease affect) } \\
\hline Control & $41.3 \pm 15.3$ & $32.7 \pm 10.5$ & $3.039 / 0.014$ \\
\hline Intervention & $40.4 \pm 16.9$ & $18.5 \pm 7.2$ & $8.158 /<0.001$ \\
\hline Intervention vs. Control (t/P-value) & $0.675 / 0.517$ & $7.229 /<0.001$ & \\
\hline \multicolumn{4}{|l|}{ SGRQ score (total) } \\
\hline Control & $46.8 \pm 17.4$ & $38.2 \pm 11.8$ & $3.126 / 0.012$ \\
\hline Intervention & $47.2 \pm 18.1$ & $27.8 \pm 8.6$ & $10.518 /<0.001$ \\
\hline Intervention vs. Control (t/P-value) & $0.444 / 0.667$ & $6.169 /<0.001$ & \\
\hline \multicolumn{4}{|l|}{ SF-36 score (general health) } \\
\hline Control & $42.2 \pm 11.2$ & $48.9 \pm 13.2$ & $3.276 / 0.010$ \\
\hline Intervention & $43.1 \pm 12.6$ & $58.1 \pm 15.2$ & $9.162 /<0.001$ \\
\hline Intervention vs. Control (t/P-value) & $1.319 / 0.220$ & $11.328 /<0.001$ & \\
\hline \multicolumn{4}{|l|}{ SF-36 score (mental health) } \\
\hline Control & $61.4 \pm 10.9$ & $68.4 \pm 18.2$ & $3.678 / 0.005$ \\
\hline Intervention & $60.1 \pm 13.2$ & $77.1 \pm 19.4$ & $5.155 /<0.001$ \\
\hline Intervention vs. Control (t/P-value) & $1.737 / 0.116$ & $5.239 /<0.001$ & \\
\hline
\end{tabular}

Data are presented as the mean \pm standard deviation. TCM, Traditional Chinese Medicine; SGRQ, St. George's Respiratory Questionnaire; SF-36, Medical Outcomes 36-Item Short Form Health Survey.

Comparison of total TCM syndrome score and quality of life. There were no significant differences in total scores of TCM symptoms, SGRQ scores in each domain and SF-36 scores between the two groups before treatment. The TCM syndrome score, SF-36 scores and SGRQ score in respiratory symptoms, activity limitation, and the total score were significantly improved in both groups at the end of week 12 compared with the scores prior to treatment (all $\mathrm{P}<0.05$; Table V). However, the total scores of TCM symptoms, SGRQ scores and SF-36 scores in the intervention group were significantly improved compared with those in the control group after 12 weeks (all $\mathrm{P}<0.05$; Table V).

Comparisons of inflammation-related factors and protease molecules before and after treatment. The expression levels of SP-D, PCT, sTREM-1, SAA, IP-10 and TRAIL, and the activities of NE, $\alpha 1-A T$, SLPI and TIMP-1 demonstrated no significant differences between the two groups before treatment. At 12 weeks, the levels of inflammation-related factors, including SP-D, PCT, sTREM-1, SAA, IP-10 and TRAIL (Fig. 2), as well as protease molecules, such as NE, $\alpha 1-\mathrm{AT}$, SLPI and TIMP-1 (Fig. 3) were all significantly ameliorated in both groups compared with 0 weeks $(\mathrm{P}<0.05)$. However, all levels and activities at 12 weeks were improved to a significantly greater extent in the intervention group compared with the control group (all $\mathrm{P}<0.05$ ).

Comparison of the Kpeal1/Nrf2/antioxidant response element (ARE) pathway in induced sputum before and after treatment. The differences in the mRNA expression levels of Keap1 and Nrf2, and the contents of superoxide anions, MDA, GST and GPX, in the induced sputum between the two groups were not significant prior to treatment ( $P>0.05$; Fig. 4). The levels of Keap1, superoxide anions and MDA were significantly 

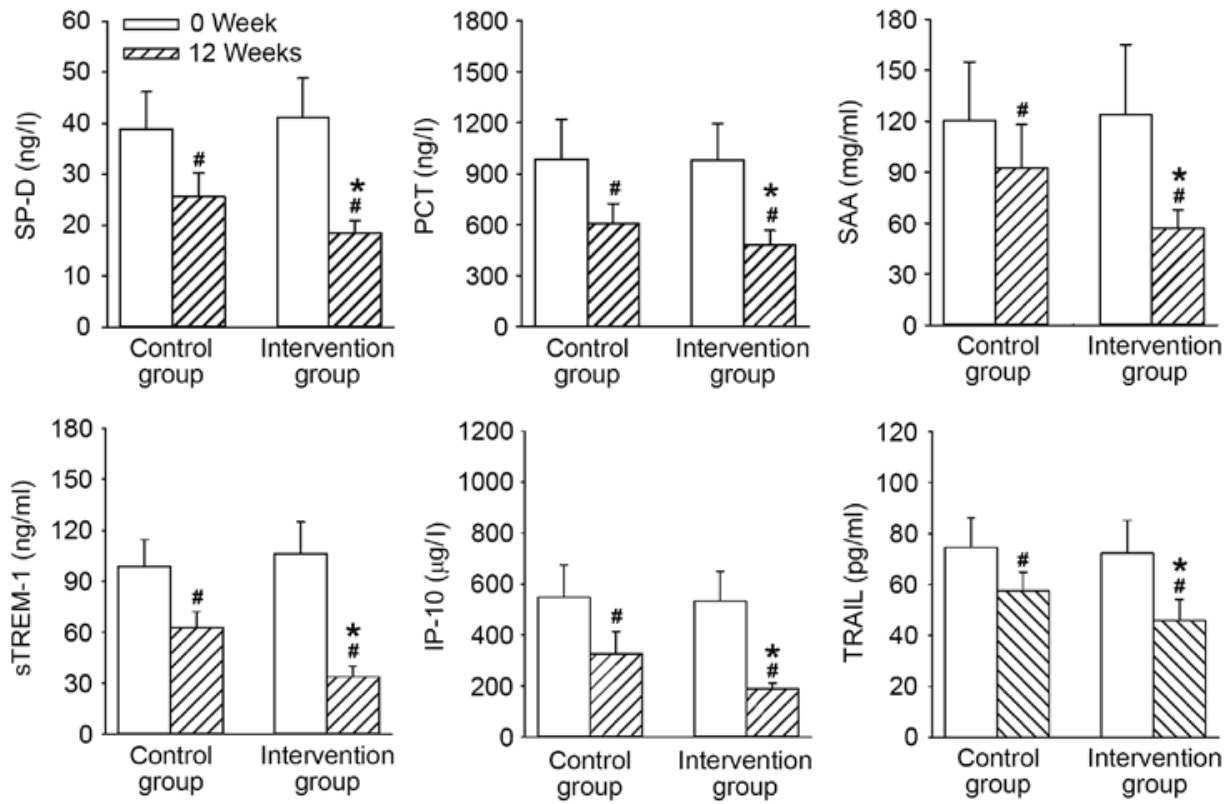

Figure 2. Comparisons of inflammation-related factors before and after treatment in the control and intervention group. Data are presented as the mean \pm standard deviation. "P<0.05 vs. the control group; ${ }^{\text {P }}<0.05$ vs. 0 week. SP-D, surfactant protein D; PCT, procalcitonin; SAA, serum amylase A; sTREM-1, soluble triggering receptor expressed on myeloid cell-1; IP-10, interferon-G induced protein 10; TRAIL, tumor necrosis factor-related apoptosis-inducing ligand.
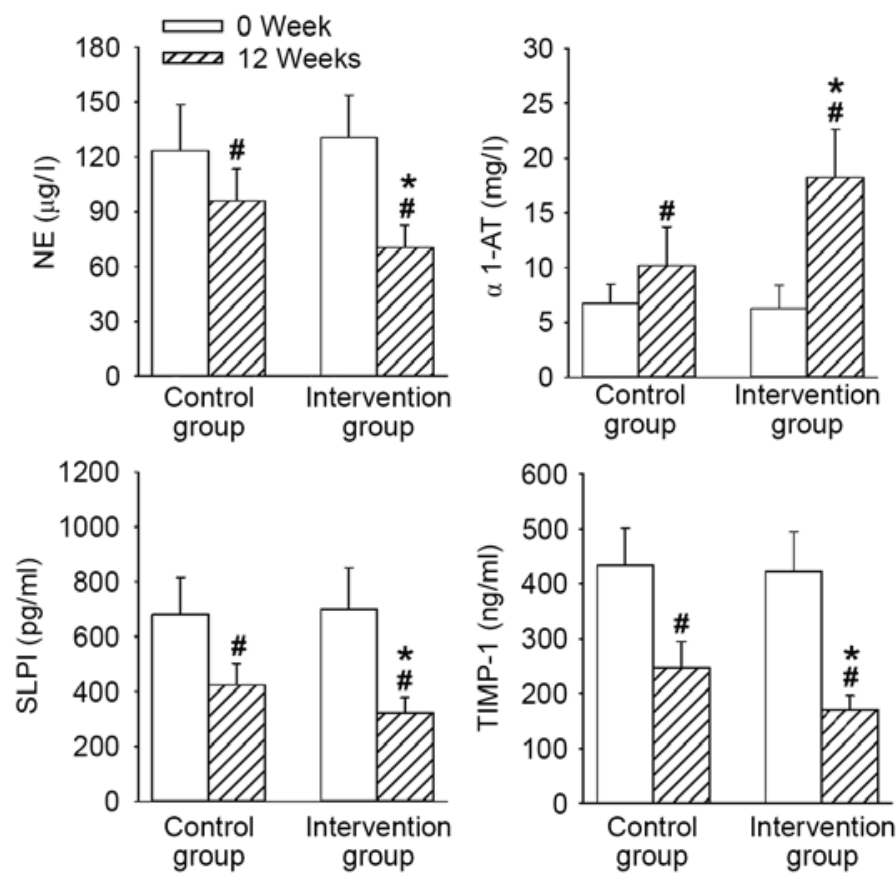

Figure 3. Comparisons of protease molecules before and after treatment in the control and intervention group. Data are presented as the mean \pm standard deviation. ${ }^{*} \mathrm{P}<0.05$ vs. the control group; ${ }^{\#} \mathrm{P}<0.05$ vs. 0 week. NE, neutrophil elastase; $\alpha 1$-AT, $\alpha 1$-antitrypsin; SLPI, secretory leukocyte protease inhibitor; TIMP-1, tissue inhibitor of metalloproteinase 1 .

decreased, and the expression levels of Nrf2, GST, GPX were significantly increased in the two groups after 12 weeks of treatment compared with 0 weeks of treatment $(\mathrm{P}<0.05)$. However, the improvement in Keap1, Nrf2, superoxide anions, MDA, GST, GPX were improved to a significantly greater extent in the intervention group compared with those in the control group over the 12 -week study period $(\mathrm{P}<0.05$; Fig. 4).

\section{Discussion}

COPD is considered as a systemic pulmonary inflammatory disease, which exerts a large threat to human physical and mental health in both developing and developed countries (26). GOLD has predicted that COPD may gradually develop to the third greatest inducer of mortality by the year 2020 around the world (27). TCM has recently demonstrated some advantages 

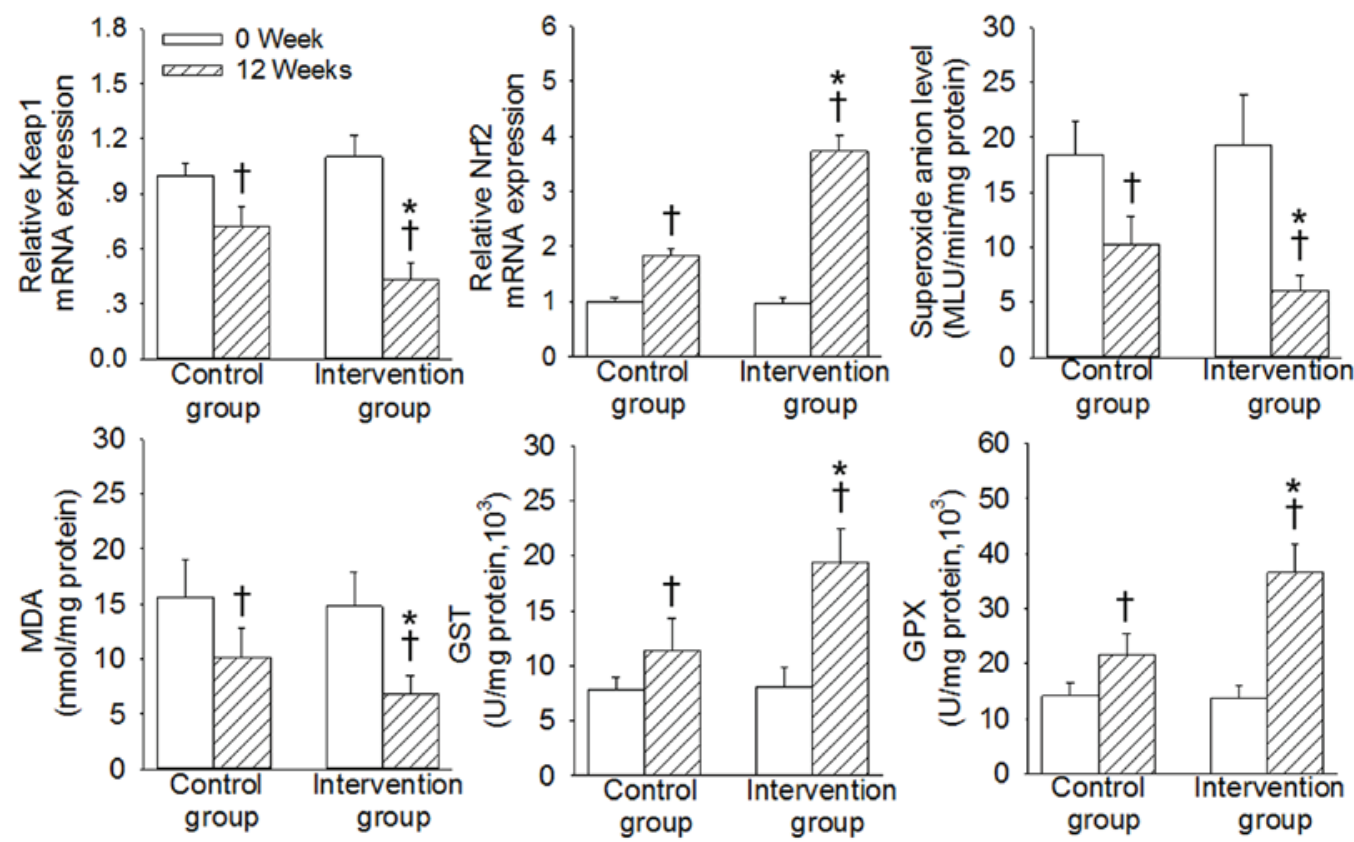

Figure 4. Comparison of expression of Keap1/Nrf2 pathway molecules in induced sputum before and after treatment in the control and intervention group. Data are presented as the mean \pm standard deviation. ${ }^{*} \mathrm{P}<0.05$ vs. the control group; ${ }^{\dagger} \mathrm{P}<0.05$ vs. 0 week. Keap1, Kelch-like ECH-associated protein; Nrf2, nuclear factor-E2-related factor-2; ARE, antioxidant response element; MDA, malondialdehyde; GST, glutathione-s-transferase; GPX, glutathione peroxidase; MLU, mean light unit.

in improvements of clinical symptoms and reductions of the exacerbation incidence of COPD (28). The present study demonstrated for the first time that combinations of western medicine with Pingchuan Guben decoction significantly ameliorated the clinical symptoms, reduced the frequency and duration of acute exacerbation, and improved the lung function and quality of life via regulation of inflammation mediators, protease molecules and activation of the Keap1/Nrf2 signaling pathway.

In China, many TCM modalities are commonly applied to prevent the development of COPD (29). Comprehensive therapy based on TCM patterns lowered the frequency of acute exacerbation and alleviated the symptoms of patients with COPD (19). Chinese medicine internal-external combined therapy markedly improved the scores of TCM syndrome and quality of life in patients with COPD (30). In the present study, the results demonstrated that the clinical efficacy rate was significantly increased in patients with COPD who received the combination of western medicine and Pingchuan Guben decoction treatment. Combined use of western medicine and Pingchuan Guben decoction treatment also reduced the frequency and duration of acute exacerbation in patients with COPD. These results indicated that the western medicine and Pingchuan Guben decoction may be taken as an effective strategy for relieving clinical syndromes and enhancing the clinical effect in patients with COPD.

COPD exerts a substantial burden on the patients and public hospital service due to repeated symptoms (31). The decrease in quality of life is closely related to individuals with COPD $(15,32,33)$. Scores for SF-36 or SGRQ are useful tools to assess the quality of life in patients with COPD (19). TCM syndrome score is an indicator for evaluation of the degree of clinical syndrome in Chinese medicines (21). Pulmonary dysfunction is clinically present as decreases in FEV1, FVC,
FEV1 \% and FEV1/FVC in patients with COPD (1). The 6 MWD is usually a good predictor of healthcare utilization in subjects with COPD (30). Complementary and alternative medicines, including TCM, are used as a complement to western medical interventions of COPD therapy associated with improvement in lung function or quality of life (34). In the present study, the results demonstrated that the mean values of $6 \mathrm{MWD}, \mathrm{FEV} 1, \mathrm{FVC}$ and FEV1/FVC in the intervention group were significantly higher than those of the control group at week 12. The TCM syndrome score, SF-36 scores and SGRQ score in respiratory symptoms, activity limitation and the total score were significantly improved in both groups at the end of week 12 . However, there were significant differences in total scores of TCM symptoms SGRQ scores and SF-36 scores in the intervention group compared with those in the control group after 12 weeks. These results suggested that the combination of western medicine with Pingchuan Guben decoction was effective in improving lung function and quality of life of patients with COPD, and these improvements were greater than those seen with the use of western medicine alone.

Inflammation has an important role in the development and progression of COPD (35). SP-D is positively associated with the severity of COPD, and SP-D may successfully differentiate COPD from other respiratory symptoms or diseases (36). Serum SP-D levels are remarkably increased in acute exacerbations of patients with COPD, and are negatively correlated with the lung function in COPD patients (37). SP-D levels in the sputum may be considered as a valuable predictive indicator of prognosis of patients with COPD treated with inhaled corticosteroids and long-acting $\beta 2$-agonists (38). PCT is a precursor of the hormone calcitonin, and PCT is expressed in neuroendocrine cells of the intestine and the lung (39). PCT has been proposed to have a prognostic importance in exacerbations of COPD $(40,41)$. 
SAA is a member of the apolipoprotein family, which contributes to the aggravation of the inflammatory response through activation of neutrophil and other inflammatory cells $(42,43)$. A previous study demonstrated that SAA levels are raised in inflammatory diseases, including COPD (44). sTREM-1 is a triggering receptor of myeloid cells, is selectively expressed in neutrophils and is crucial for the activation of neutrophils (45). IP-10 may induce the activation of monocytes and $\mathrm{T}$ lymphocytes, and is positively related to higher IL-6 levels in COPD. The accumulation of IP-10 predicates a poor outcome of treatment for patients with COPD (46). Expression of TRAIL, a member of the tumor necrosis factor family, is markedly higher in COPD patients than in healthy controls (47). Increased TRAIL levels were associated with lung dysfunction and systemic inflammation in patients with COPD (48). NE belongs to the serine protease superfamily, and has a critical role in inflammatory damage and lung injury. NE is also vital for the induction of expressions of granulocyte stimulating factor and IL-6 (49). $\alpha 1-A T$ is a type of protease inhibitor, which is responsible for the prevention of cathepsins release (50). A previous study demonstrated that patients with $\alpha 1$-AT deficiency present higher NE levels and early formation of emphysema (51). SLPI is recognized as a member of the whey acidic protein four-disulfide core family, and is abundantly produced by epithelial cells, neutrophils and macrophages in the digestive, respiratory and reproductive tracts (52). The SLPI level is higher and is negatively correlated with FEV/FVC in patients with COPD (53). A prospective study proposed that the expression of TIMP-1 in exhaled breath condensate is higher in patients with stable COPD (54). The increased TIMP-1 expression is closely related with COPD exacerbation (54). In the present study, it was demonstrated that the levels of inflammation-related factors, including SP-D, PCT, sTREM-1, SAA, IP-10 and TRAIL, as well as protease molecules such as NE, $\alpha 1-\mathrm{AT}$, SLPI and TIMP-1, were significantly ameliorated in the intervention group compared with the control group at 12 weeks. These results indicated that combination of western medicine with Pingchuan Guben decoction effectively reduced the severity of systemic inflammation, and improved the ability of the body to clear the protease for effective inhibition of the inflammatory reaction.

Oxidative stress is a critical factor that is involved in the development of COPD $(55,56)$. The systemic or local imbalance in oxidation/antioxidation is always presented in the acute exacerbation period and stable period of COPD (28). The correction of oxidant/antioxidant imbalance has become a novel approach in the treatment of COPD (57). The Keap1/Nrf2 signaling pathway has recently been demonstrated to be a defensive transduction pathway for the resistance to oxidation and chemical stimulation (58). Nrf2 is dissociated from Keap1 to stabilize these antioxidant factors. Nrf2 is vital for the ARE-mediated expression of antioxidative enzymes, which has a protective role in the prevention of cell damage induced by oxidative stress (59). Nrf2 and its gene targets are crucial endogenous antioxidative components against oxidative stress (60). Keap1 is well known as an endogenous inhibitor of Nrf2 in the cytoplasm. Nrf2 dissociates from Keap1 under oxidative stress, which is a necessary step for the induction of various antioxidant genes, including GPX and GST (61). The present results revealed that the levels of Keap1, superoxide anions and MDA were significantly decreased, and the expression of Nrf2, GST and GPX were significantly increased in the two groups after 12 weeks of treatment. However, the improvements in Keap1, Nrf2, superoxide anions, MDA, GST and GPX were greater in the intervention group than in the control group over the 12 -week study period. These data indicated the key mechanisms involved in combination treatment using western medicine and Pingchuan Guben decoction for the treatment of COPD.

In conclusion, combinations of western medicine with Pingchuan Guben decoction may reduce the systemic inflammatory response and enhance antioxidant and anti-inflammatory function to effectively treat patients with COPD. In addition, multi-center, large-sample clinical trials are required for the measurement of long-term efficacy, safety and tolerability of Pingchuan Guben decoction.

\section{References}

1. Tian Y, Li Y, Li J, Xie Y, Wang M, Dong Y, Li L, Mao J, Wang L and Luo S: Bufei Yishen granule combined with acupoint sticking improves pulmonary function and morphormetry in chronic obstructive pulmonary disease rats. BMC Complement Altern Med 15: 266, 2015.

2. Tanash HA, Ekstrom M, Wagner P and Piitulainen E: Cause-specific mortality in individuals with severe alpha 1-antitrypsin deficiency in comparison with the general population in Sweden. Int J Chron Obstruct Pulmon Dis 11: 1663-1669, 2016.

3. Marrie RA, Patten S, Tremlett H, Svenson LW, Wolfson C, Yu BN, Elliott L, Profetto-McGrath J, Warren S, Leung S, et al: Chronic lung disease and multiple sclerosis: Incidence, prevalence, and temporal trends. Mult Scler Relat Disord 8: 86-92, 2016.

4. Jin J, Yu W, Li S, Lu L, Liu X and Sun Y: Factors associated with bronchiectasis in patients with moderate-severe chronic obstructive pulmonary disease. Medicine (Baltimore) 95: e4219, 2016.

5. Gelberg J and McIvor RA: Overcoming gaps in the management of chronic obstructive pulmonary disease in older patients: New insights. Drugs Aging 27: 367-375, 2010.

6. Romanelli AM, Raciti M, Protti MA, Prediletto R, Fornai E and Faustini A: Correction: How reliable are current data for assessing the actual prevalence of chronic obstructive pulmonary disease? PLoS One 11: e0159222, 2016.

7. Kharbanda S, Ramakrishna A and Krishnan S: Prevalence of quadriceps muscle weakness in patients with COPD and its association with disease severity. Int J Chron Obstruct Pulmon Dis 10: 1727-1735, 2015.

8. Reynaert NL, Gopal P, Rutten EP, Wouters EF and Schalkwijk CG: Advanced glycation end products and their receptor in age-related, non-communicable chronic inflammatory diseases; Overview of clinical evidence and potential contributions to disease. Int J Biochem Cell Biol 81: 403-408, 2016.

9. Lee KY, Feng PH, Ho SC, Chuang KJ, Chen TT, Su CL, Liu WT and Chuang HC: Inter-alpha-trypsin inhibitor heavy chain 4: A novel biomarker for environmental exposure to particulate air pollution in patients with chronic obstructive pulmonary disease. Int J Chron Obstruct Pulmon Dis 10: 831-841, 2015.

10. Dong L, Xia JW, Gong Y, Chen Z, Yang HH, Zhang J, He J and Chen XD: Effect of lianhuaqingwen capsules on airway inflammation in patients with acute exacerbation of chronic obstructive pulmonary disease. Evid Based Complement Alternat Med 2014: 637969, 2014

11. Wang Y, Lin Z, Huang H, He H, Yang L, Chen T, Yang T, Ren N, Jiang $\mathrm{Y}$ and $\mathrm{Xu} \mathrm{W}$ : AMPK is required for PM2.5-induced autophagy in human lung epithelial A549 cells. Int J Clin Exp Med 8: 58-72, 2015.

12. Domej W, Oettl K and Renner W: Oxidative stress and free radicals in COPD-implications and relevance for treatment. Int $\mathbf{J}$ Chron Obstruct Pulmon Dis 9: 1207-1224, 2014.

13. Watson WH, Ritzenthaler JD and Roman J: Lung extracellular matrix and redox regulation. Redox Biol 8: 305-315, 2016. 
14. Johnson K, McEvoy CE, Naqvi S, Wendt C, Reilkoff RA, Kunisaki KM, Wetherbee EE, Nelson D, Tirouvanziam R and Niewoehner DE: High-dose oral $\mathrm{N}$-acetylcysteine fails to improve respiratory health status in patients with chronic obstructive pulmonary disease and chronic bronchitis: A randomized, placebo-controlled trial. Int J Chron Obstruct Pulmon Dis 11: 799-807, 2016.

15. Chen HQ, Zou SH, Yang JB, Cai J, Zhang Y and Wang ZL: A survey and analysis of using traditional Chinese medicine during pregnancy. Int J Clin Exp Med 8: 19496-19500, 2015.

16. Tsou YA, Huang HJ, Lin WW and Chen CY: Lead Screening for Chronic Obstructive Pulmonary Disease of IKK2 Inhibited by Traditional Chinese Medicine. Evid Based Complement Alternat Med 2014: 465025, 2014.

17. Xiao B, Wang M, Hu X, Li J, Wang F and Sun J: Antibiotic de-escalation principle in elderly patients with chronic obstructive pulmonary disease complicated with severe pneumonia. Exp Ther Med 13: 1485-1489, 2017

18. Oda N, Miyahara N, Ichikawa H, Tanimoto Y, Kajimoto K, Sakugawa M, Kawai H, Taniguchi A, Morichika D, Tanimoto M, et al: Long-term effects of beta-blocker use on lung function in Japanese patients with chronic obstructive pulmonary disease. Int J Chron Obstruct Pulmon Dis 12: 1119-1124, 2017.

19. Li SY, Li JS, Wang MH, Xie Y, Yu XQ, Sun ZK, Ma LJ, Zhang W, Zhang HL, Cao F and Pan YC: Effects of comprehensive therapy based on traditional Chinese medicine patterns in stable chronic obstructive pulmonary disease: A four-center, open-label, randomized, controlled study. BMC Complement Altern Med 12: 197, 2012.

20. Selman L, McDermott K, Donesky D, Citron $\mathrm{T}$ and Howie-Esquivel J: Appropriateness and acceptability of a Tele-Yoga intervention for people with heart failure and chronic obstructive pulmonary disease: Qualitative findings from a controlled pilot study. BMC Complement Altern Med 15: 21, 2015

21. Guo S, Sun Z, Liu E, Feng J, Fu M, Li Y and Wu Q: Effect of bufei granule on stable chronic obstructive pulmonary disease: A randomized, double blinded, placebo-controlled, and multicenter clinical study. J Tradit Chin Med 34: 437-444, 2014.

22. Zheng J, Zhong N, Newlands A, Church A and Goh AH: Efficacy and safety of once-daily inhaled umeclidinium/vilanterol in Asian patients with COPD: Results from a randomized, placebo-controlled study. Int J Chron Obstruct Pulmon Dis 10: 1753-1767, 2015.

23. Kleniewska A, Walusiak-Skorupa J, Piotrowski W Nowakowska-Swirta E and Wiszniewska M: Comparison of biomarkers in serum and induced sputum of patients with occupational asthma and chronic obstructive pulmonary disease. J Occup Health 58: 333-339, 2016.

24. Livak KJ and Schmittgen TD: Analysis of relative gene expression data using real-time quantitative PCR and the 2(-Delta Delta C(T)) method. Methods 25: 402-408, 2001

25. Sun HJ, Zhang LL, Fan ZD, Chen D, Zhang L, Gao XY, Kang YM and Zhu GQ: Superoxide anions involved in sympathoexcitation and pressor effects of salusin- $\beta$ in paraventricular nucleus in hypertensive rats. Acta Physiol (Oxf) 210: 534-545, 2014

26. Zhou X, Li Q and Zhou X: Exacerbation of Chronic Obstructive Pulmonary Disease. Cell Biochem Biophys 73: 349-355, 2015.

27. Sharma RK and Chakrabarti S: Anaemia secondary to erythropoietin resistance: Important predictor of adverse outcomes in chronic obstructive pulmonary disease. Postgrad Med J, 2016 (Epub ahead of print)

28. Boskabady MH and Gholami Mahtaj L: Lung inflammation changes and oxidative stress induced by cigarette smoke exposure in guinea pigs affected by Zataria multiflora and its constituent, carvacrol. BMC Complement Altern Med 15: 39, 2015.

29. Gong SG, Yang WL, Liu JM, Liu WZ and Zheng W: Change in pulmonary function in chronic obstructive pulmonary disease stage 0 patients. Int J Clin Exp Med 8: 21400-21406, 2015.

30. Zheng F, Li GQ and Bian YJ: Effects of Chinese medicine internal-external combined therapy in treating chronic obstructive pulmonary disease in the stable period. Zhongguo Zhong Xi Yi Jie He Za Zhi 30: 369-372, 2010 (In Chinese).

31. Leem AY, Kim SK, Chang J, Kang YA, Kim YS, Park MS, Kim SY, Kim EY, Chung KS and Jung JY: Relationship between blood levels of heavy metals and lung function based on the Korean National Health and Nutrition Examination Survey IV-V. Int J Chron Obstruct Pulmon Dis 10: 1559-1570, 2015.

32. Cheruvu VK, Odhiambo LA, Mowls DS, Zullo MD and Gudina AT: Health-related quality of life in current smokers with COPD: Factors associated with current smoking and new insights into sex differences. Int J Chron Obstruct Pulmon Dis 11: 2211-2219, 2016.
33. Deslee G, Burgel PR, Escamilla R, Chanez P, Court-Fortune I, Nesme-Meyer P, Brinchault-Rabin G, Perez T, Jebrak G, Caillaud D, et al: Impact of current cough on health-related quality of life in patients with COPD. Int J Chron Obstruct Pulmon Dis 11: 2091-2097, 2016.

34. Cui Z, Tian Y, He B, Li H, Li D, Liu J, Cai H, Lou J, Jiang H, Shen X and Peng K: Associated factors of radiation pneumonitis induced by precise radiotherapy in 186 elderly patients with esophageal cancer. Int J Clin Exp Med 8: 16646-16651, 2015.

35. Abd El-Kader SM and Al-Jiffri OH: Exercise alleviates depression related systemic inflammation in chronic obstructive pulmonary disease patients. Afr Health Sci 16: 1078-1088, 2016

36. Akiki Z, Fakih D, Jounblat R, Chamat S, Waked M, Holmskov U, Sorensen GL, Nadif R and Salameh P: Surfactant protein D, a clinical biomarker for chronic obstructive pulmonary disease with excellent discriminant values. Exp Ther Med 11: 723-730, 2016.

37. Zien Alaabden A, Mohammad Y and Fahoum S: The role of serum surfactant protein D as a biomarker of exacerbation of chronic obstructive pulmonary disease. Qatar Med J 2015: 18 , 2016.

38. Liu W, Ju CR, Chen RC and Liu ZG: Role of serum and induced sputum surfactant protein $\mathrm{D}$ in predicting the response to treatment in chronic obstructive pulmonary disease. Exp Ther Med 8: 1313-1317, 2014.

39. Russwurm S, Stonans I, Stonane E, Wiederhold M, Luber A Zipfel PF, Deigner HP and Reinhart K: Procalcitonin and CGRP-1 mrna expression in various human tissues. Shock 16: 109-112, 2001.

40. Ergan B, Sahin AA and Topeli A: Serum Procalcitonin as a Biomarker for the prediction of bacterial exacerbation and mortality in severe COPD exacerbations requiring mechanical ventilation. Respiration 91: 316-324, 2016.

41. Lacoma A, Prat C, Andreo F, Lores L, Ruiz-Manzano J, Ausina V and Domínguez J: Value of procalcitonin, C-reactive protein, and neopterin in exacerbations of chronic obstructive pulmonary disease. Int J Chron Obstruct Pulmon Dis 6: 157-169, 2011.

42. Bozinovski S, Anthony D and Vlahos R: Targeting pro-resolution pathways to combat chronic inflammation in COPD. J Thorac Dis 6: 1548-1556, 2014

43. Bozinovski S, Vlahos R, Anthony D, McQualter J, Anderson G, Irving L and Steinfort D: COPD and squamous cell lung cancer: aberrant inflammation and immunity is the common link. Br J Pharmacol 173: 635-648, 2016.

44. Oluwatowoju IO, Abu OE and Lawson G: Abdominal pain and a raised amylase? It's not always pancreatitis. Acute Med 12: 163-165, 2013.

45. Molad Y, Pokroy-Shapira E, Kaptzan T, Monselise A, Shalita-Chesner M and Monselise Y: Serum soluble triggering receptor on myeloid cells-1 (sTREM-1) is elevated in systemic lupus erythematosus but does not distinguish between lupus alone and concurrent infection. Inflammation 36: 1519-1524, 2013.

46. Heulens N, Korf H, Cielen N, De Smidt E, Maes K, Gysemans C, Verbeken E, Gayan-Ramirez G, Mathieu C and Janssens W: Vitamin D deficiency exacerbates COPD-like characteristics in the lungs of cigarette smoke-exposed mice. Respir Res 16: 110, 2015.

47. Kochetkova EA, Nevzorova VA, Ugai LG, Maistrovskaia YV and Massard G: The role of tumor necrosis factor Alpha and TNF superfamily members in bone damage in patients with end-stage chronic obstructive lung disease prior to lung transplantation. Calcif Tissue Int 99: 578-587, 2016.

48. Wu Y, Shen Y, Zhang J, Wan C, Wang T, Xu D, Yang T and Wen F: Increased serum TRAIL and DR5 levels correlated with lung function and inflammation in stable COPD patients. Int J Chron Obstruct Pulmon Dis 10: 2405-2412, 2015.

49. Victoni T, Gicquel T, Bodin A, Daude M, Tenor H, Valenç S, Devillier P, Porto LC, Lagente V and Boichot E: Roflumilast n-oxide associated with PGE2 prevents the neutrophil elastase-induced production of chemokines by epithelial cells. Int Immunopharmacol 30: 1-8, 2016.

50. Bunatova K, Obermajer N, Kotyza J, Pesek M and Kos J: Levels of cathepsins $\mathrm{S}$ and $\mathrm{H}$ in pleural fluids of inflammatory and neoplastic origin. Int J Biol Markers 24: 47-51, 2009.

51. Ungurs MJ, Sinden NJ and Stockley RA: Progranulin is a substrate for neutrophil-elastase and proteinase- 3 in the airway and its concentration correlates with mediators of airway inflammation in COPD. Am J Physiol Lung Cell Mol Physiol 306: L80-L87, 2014. 
52. Nukiwa T, Suzuki T, Fukuhara T and Kikuchi T: Secretory leukocyte peptidase inhibitor and lung cancer. Cancer Sci 99: 849-855, 2008

53. Hollander C, Sitkauskiene B, Sakalauskas R, Westin U and Janciauskiene SM: Serum and bronchial lavage fluid concentrations of IL-8, SLPI, sCD14 and sICAM-1 in patients with COPD and asthma. Respir Med 101: 1947-1953, 2007.

54. Kwiatkowska S, Noweta K,Zieba M,Nowak D and Bialasiewicz P Enhanced exhalation of matrix metalloproteinase-9 and tissue inhibitor of metalloproteinase-1 in patients with COPD exacerbation: A prospective study. Respiration 84: 231-241, 2012.

55. Nesi RT, de Souza PS, Dos Santos GP, Thirupathi A, Menegali BT, Silveira PC, da Silva LA, Valença SS and Pinho RA: Physical exercise is effective in preventing cigarette smoke-induced pulmonary oxidative response in mice. Int $\mathrm{J}$ Chron Obstruct Pulmon Dis 11: 603-610, 2016.

56. Fischer BM,Pavlisko E and Voynow JA: Pathogenic triad in COPD: Oxidative stress, protease-antiprotease imbalance, and inflammation. Int J Chron Obstruct Pulmon Dis 6: 413-421, 2011.
57. Toru U, Ayada C, Genc O, Turgut S, Turgut G and Bulut I: MDR-1 gene C/T polymorphism in COPD: Data from Aegean part of Turkey. Int J Clin Exp Med 7: 3573-3577, 2014

58. Cheng L, Jin Z, Zhao R, Ren K, Deng C and Yu S: Resveratrol attenuates inflammation and oxidative stress induced by myocardial ischemia-reperfusion injury: Role of Nrf2/ARE pathway. Int J Clin Exp Med 8: 10420-10428, 2015.

59. Zeng X, Li J and Li Z: Ginsenoside Rd mitigates myocardial ischemia-reperfusion injury via $\mathrm{Nrf} 2 / \mathrm{HO}-1$ signaling pathway. Int J Clin Exp Med 8: 14497-14504, 2015.

60. Kwon OJ, Choo BK, Lee JY, Kim MY, Shin SH, Seo BI, Seo YB, Rhee MH, Shin MR, Kim GN, et al: Protective effect of Rhei Rhizoma on reflux esophagitis in rats via Nrf2-mediated inhibition of NF- $\mathrm{KB}$ signaling pathway. BMC Complement Altern Med 16: 7, 2016.

61. Yang SP, Yang XZ and Cao GP: Acetyl-1-carnitine prevents homocysteine-induced suppression of Nrf2/Keap1 mediated antioxidation in human lens epithelial cells. Mol Med Rep 12: 1145-1150, 2015. 